\title{
A Scientometric Analysis of 20 Years of Research on Breast Reconstruction Surgery: A Guide for Research Design and Journal Selection
}

\author{
Mehrdad Moghimi ${ }^{1}$, Mehdi Fathi ${ }^{1}$, Ali Marashi ${ }^{1}$, Freshteh Kamani ${ }^{1}$, Gholamreza Habibi ${ }^{2}$, \\ Armin Hirbod-Mobarakeh'2, Marjan Ghaemi ${ }^{2}$, Mahdi Hosseinian-Sarajehlou ${ }^{3}$ \\ ${ }^{1}$ Department of Surgery, Shahid Beheshti University of Medical Sciences, Tehran; ${ }^{2}$ Farzan Scientometric Group, Farzan Clinical \\ Research Institute, Tehran; ${ }^{3}$ Breast Cancer Research Center, Iranian Center of Breast Cancer Academic Center for Education, Culture and \\ Research, Tehran, Iran
}

Background Breast reconstruction refers to the rebuilding of a woman's breast using autologous tissue or prosthetic material to form a natural-looking breast. It is increasingly offered to women undergoing mastectomy for breast cancer. However, there is no systematic analysis available for the expanding area of research on breast reconstruction.

Methods A bibliometric method was used to obtain a view of the scientific production about breast reconstruction by data extracted from the Institute for Scientific Information (ISI). Specific parameters were retrieved from the ISI. Articles about breast reconstruction were analyzed to obtain a view of the topic's structure, history, and document relationships using HistCite software. Trends in the most influential publications and authors were analyzed.

Results The number of articles was constantly increasing. Most highly cited articles described the methods of flap construction in the surgery. Other highly cited articles discussed the psychological or emotional aspects of breast reconstruction, skin sparing mastectomy, and breast reconstruction in the irradiated breast.

Conclusions This was the first breast reconstruction scientometric analysis, representing the characteristics of papers and the trends of scientific production. A constant increase in the number of breast reconstruction papers and also the increasing number of citations shows that there is an increasing interest in this area of medical science. It seems that most of the research in this field is focused on the technical aspects of surgery.

Keywords Mammaplasty / Bibliometrics / Historiography
Correspondence:

Mahdi Hosseinian-Sarajehlou Breast Cancer Research Center, Iranian Center for Breast Cancer, Academic Center for Education, Culture and Research, P.O. Box. 13185-1678, Tehran, Iran

Tel: +98-21-66423101

Fax: +98-21-66423304

E-mail:swt_f@yahoo.com
This article contains supplemental appendix 1 .

We appreciate Farzan Institute for Research and Technology for technical assistance.

No potential conflict of interest relevant to this article was reported.

\section{INTRODUCTION}

Breast reconstruction is the remaking of a women's breast to correct the disfigurement resulting from mastectomy in women with breast cancer, which affects one in every nine women in the United States [1]. Mastectomy is frequently needed in the management of breast cancer, so breast reconstruction has been increasingly incorporated into the management of patients diagnosed with breast cancer [2-4]. One option for reconstruction is insertion of breast implants such as saline-filled and silicone

Copyright $($ C 2013 The Korean Society of Plastic and Reconstructive Surgeons

This is an Open Access article distributed under the terms of the Creative Commons Attribution Non-Commercial License (http://creativecommons.org/

licenses/by-nc/3.0/) which permits unrestricted non-commercial use, distribution, and reproduction in any medium, provided the original work is properly cited.

www.e-aps.org 
gel-filled implants. Use of the patients' own tissues (autologous reconstruction) such as abdominal muscles is another option for patients [1].

The first mastectomy was performed in 1889 by William Halsted to surgically control breast cancer [5]. With more appraisal of the necessity of mastectomy for breast cancer patients, the field of breast reconstruction evolved. Czerny [6], a professor of surgery at Heidelberg, performed the first true breast reconstruction surgery in 1895 [6]. Developments in breast reconstruction ranged from the "walking flap" of Gilles to the free perforator flap using autogenous tissue for recreation of a breast "mound". Use of tissue expanders for breast reconstruction has also been improved over the last three decades. Breast reconstruction has now become an advantageous choice for women undergoing mastectomy [7].

The breast cancer rate increased 3.8\% per year through the 1980s, but it has been stable from the 1990s to the present [8]. Breast reconstructive techniques have significantly evolved over the past several decades, and in the last decades of the 20th century these techniques were critically evaluated to recommend the best management strategy. In 1990, the US National Institutes of Health recommended breast-conserving surgery"lumpectomy" in which only the tumor and surrounding tissues are removed-along with radiation as the preferred treatment for unilateral breast cancer [9]; thus breast reconstruction became an important part of the management of these patients $[10,11]$. In the United States, the overall rate for mastectomy patients undergoing reconstruction rose from $4.3 \%$ in 1988 to $10.8 \%$ in 1995 (a two-fold increase) [12]. As the requests for this surgery rose, the attention of researchers to this field also increased. Therefore, many investigators have published articles in this field in the last two decades. However, there has been no systematic analysis of this increasing number of papers. The bibliometric method is useful for assessing the scientific advancements and motivations of researchers and determining current research directions in a specific field; such data would be extremely useful for guiding subsequent research designs as it will predict how this field would move forward $[13,14]$. The aim of this study was to perform a scientometric analysis of articles on breast reconstruction from 1990 to 2010 by bibliometric indicators using the Institute for Scientific Information (ISI) Web of Science.

\section{METHODS}

\section{Data source}

A descriptive bibliometric study of scientific papers about breast reconstruction was conducted. For this aim, the ISI Web of Science database, available at http://www.isiknowledge.com was chosen because it is one of the major sources for bibliometric, citation and other academic impact information of scientific articles in various branches of sciences. The prevalence of breast cancer in different countries was retrieved from the World Health Organization website [15].

\section{Search strategies}

For choosing the best keywords, the list of Medical Subject Headings provided by the National Library of Medicine to index the contents of PubMed was considered. The adopted search strategy was as follows: breast reconstruct ${ }^{*}$ was used as a search keyword, which yielded a total of 3,259 publications. The '* ' is a wildcard that can take any value. Our search covered papers published between 1990 and 2010 and was performed on May 20, 2011. All retrieved documents, including original articles, review articles, case reports, letters, and meeting abstracts were included in the analysis.

\section{Data analysis}

Specific parameters such as the publication year, articles' language, geographical distribution, first author, main journals in this field, citations of the paper by other papers, and institutional affiliations were retrieved from the ISI and analyzed using the Analyze function provided by the ISI database. Each journal's impact factor was retrieved from the Journal Citation Reports available at http://scientific.thomson.com/products/jcr. All statistical analyses were performed using Microsoft Excel 2003 computer spreadsheet software.

Articles about breast reconstruction were analyzed to obtain a view of the topic's structure, history, and document relationships using HistCite software. The bibliography retrieved from the Web of Science database was imported to HistCite. A historiography of the breast reconstruction field between 1990 and 2010 was created by including articles that had been cited 60 or more times. 99 documents which had these characteristics are listed in Supplemental Appendix 1.

\section{RESULTS}

There was a total of 3,259 articles on breast reconstruction in the ISI Web of Science during 1990-2010, of which, 1,911 (58.6\%) were articles, 472 (14.5\%) proceeding papers, 304 (9.3\%) letters, 190 (5.8\%) editorial materials, 185 (5.7\%) meeting abstracts, $125(3.8 \%)$ reviews, and $32(1.0 \%)$ notes.

\section{Annual publication number during 1990-2010}

In Fig. 1, time trend of the number of articles is shown. The 377 published articles in 2010 compared to 30 articles in 1990 shows 
a 12-fold increase. A historiography of the articles that have been cited more than 60 times is shown in Fig. 2.

\section{Citation profile of articles}

In total, 3,259 articles related to breast reconstruction published since 1990 were cited 34,894 times. The average citations per

\section{Fig. 1. Time trend of number of articles}

Time trend of number of articles published in the field of breast reconstruction research (1990-2010).

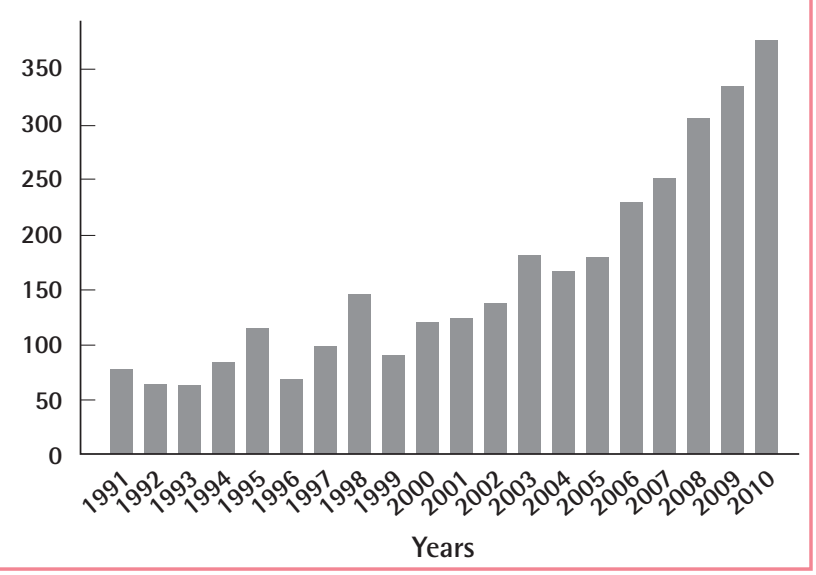

paper $(\mathrm{C} / \mathrm{P})$ was 10.71 . The $\mathrm{H}$-index is based on the distribution of citations received by a given scientist/journal. A scientist/journal has an index $\mathrm{H}$ if $\mathrm{H}$ of its $\mathrm{N}_{\mathrm{p}}$ papers have been cited at least $\mathrm{H}$ times each, and the other $\left(\mathrm{N}_{\mathrm{p}}-\mathrm{H}\right)$ papershave been cited no more than $\mathrm{H}$ times each. In other words, a publishing source (scientist/journal) with an index of $\mathrm{H}$ has published $\mathrm{H}$ papers, each of which has been cited in other papers at least $\mathrm{H}$ times. Thus, the $\mathrm{H}$-index reflects both the number of articles and the number of citations per article.

The H-index of all articles was 70,888 articles, among which 3,259 remained uncited (27\%). Thirty-nine articles (1.1\%) were cited more than 100 times. Two articles had been cited more than 300 times. Table 1 shows the journals which published the articles that had been cited 100 or more times. Fig. 3 shows the trend of citations during the period (Supplemental Appendix 1).

\section{Subject analysis and publisher of documents}

The most common topics of papers were surgery (77.8\%), oncology (15.8\%), and obstetrics and gynecology (4\%). Table 2 shows the top journals with the largest number of documents on breast reconstruction.

\section{Fig. 2. Historiography of breast reconstruction literature}

Historiography of the breast reconstruction literature regarding articles that had been cited more than 60 times. The circles represent papers. The size of the circle is relative to that paper's citations. The number inside the circle is the article number. An arrow pointing from one article to the next, usually to an older paper, indicates the citational relationship between papers, that is, the arrowhead points to the article that was cited.

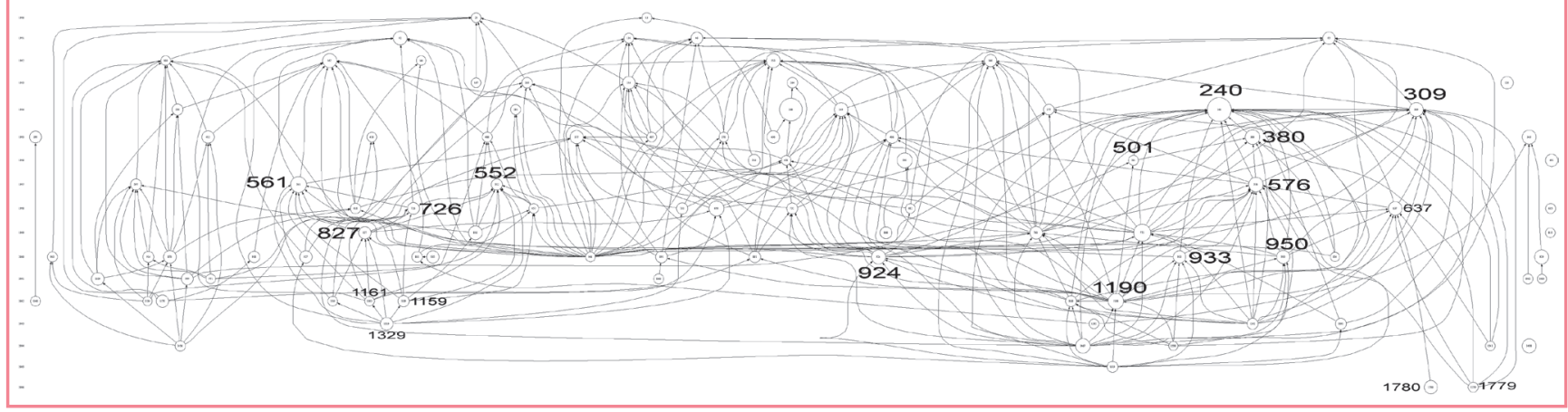

Table 1. Journals in which highly cited articles (more than 100 citations) were published

\begin{tabular}{|c|c|c|c|}
\hline Name of journal & No. of cited articles & 5-Year impact factor & Citations per paper \\
\hline New England Journal of Medicine & 1 & 51.41 & 388 \\
\hline Annals of Plastic Surgery & 2 & 1.482 & 250.5 \\
\hline Annals of Surgery & 2 & 9.502 & 141 \\
\hline British Journal of Plastic Surgery & 5 & & 140 \\
\hline Cancer & 1 & 5.551 & 132 \\
\hline Journal of the National Cancer Institute & 2 & 15.620 & 130 \\
\hline Plastic and Reconstructive Surgery & 22 & 3.158 & 122.45 \\
\hline Journal of Plastic Reconstructive and Aesthetic Surgery & 1 & 1.610 & 115 \\
\hline European Journal of Cancer & 1 & 4.388 & 103 \\
\hline Annals of Surgical Oncology & 1 & 4.443 & 102 \\
\hline Surgery & 1 & 3.793 & 100 \\
\hline
\end{tabular}




\section{Geographical distribution}

In general, 68 countries contributed to the promotion of the field of breast reconstruction by publishing articles. North American countries (the US, Canada, Mexico), with 1,496 articles (45.9\%), are the main source of breast reconstruction studies. The United States, with 1,408 (43.2\%) articles, is the most ac-

\section{Fig. 3. Time-trend of citations of articles}

Time-trend of citations of articles about breast reconstruction between 1990 and 2011.

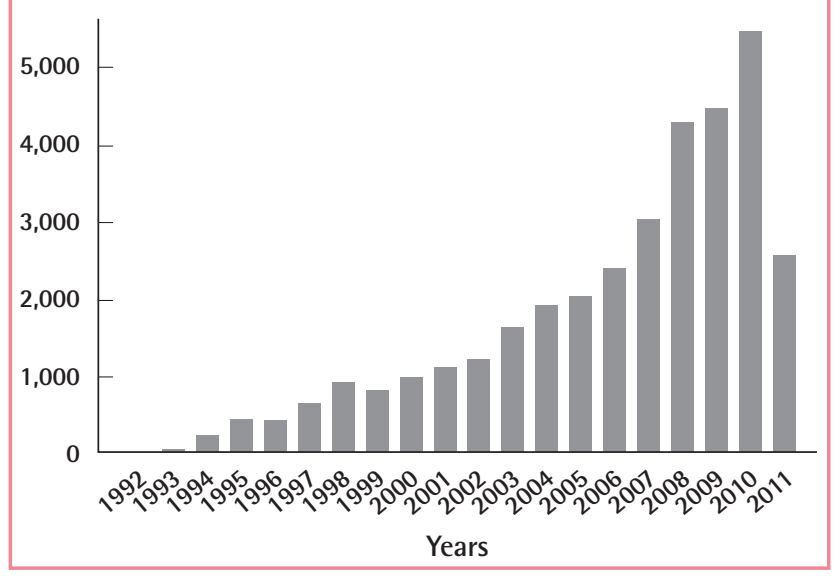

tive country in this field. Among European countries, the United Kingdom, with 354 (10.86\%) articles, ranked first, followed by Germany. Among Asian countries, Japan, with 91 (2.79\%), ranked first, followed by Turkey, with 55 (1.68\%), and South Korea, with 45 (1.38\%) articles (Table 3).

\section{Language and author profiles of publications}

Most breast reconstruction articles were in English (95.61\%) followed by German (1.99\%), French (1.9\%), and Spanish (0.18 $\%)$. In total, the articles were written in eight languages. Stephen Kroll, with 63 articles (1.93\%), had the largest number of publications in the field of breast reconstruction. William Rosen from the University of Melbourne, with 56 articles (1.72\%); Mark Ashton from the University of Melbourne, with 43 articles (1.32\%); and Maurice Nahabedian, Georgetown University, with 39 articles $(1.2 \%)$ had also published a large number of articles in this field (Table 4). Most of the top ten universities and institutions in the list are from the United States. The first two of them are the University of Texas and Sloan Kettering Cancer Center with 137 (4.2\%) and 72 (2.2\%) articles respectively, and the third is Harvard University (Table 5).

Table 2. Top journals publishing articles in the field of breast reconstruction

\begin{tabular}{|c|c|c|c|}
\hline Name of journal & Record count & Percent $(\%)$ & 5-year impact factor \\
\hline Plastic and Reconstructive Surgery & 950 & 29.15 & 3.158 \\
\hline Annals of Plastic Surgery & 437 & 13.41 & 1.482 \\
\hline Journal of Plastic Reconstructive and Aesthetic Surgery & 162 & 4.97 & 1.610 \\
\hline British Journal of Plastic Surgery & 122 & 3.74 & - \\
\hline Aesthetic Plastic Surgery & 77 & 2.36 & 1.286 \\
\hline Journal of Reconstructive Microsurgery & 75 & 2.30 & 0.884 \\
\hline Microsurgery & 70 & 2.15 & 0.740 \\
\hline Clinics in Plastic Surgery & 67 & 2.06 & 1.255 \\
\hline Annals of Surgical Oncology & 52 & 1.60 & 4.443 \\
\hline Scandinavian Journal of Plastic and Reconstructive Surgery and Hand Surgery & 52 & 1.60 & 0.74 \\
\hline
\end{tabular}

Table 3. Geographical distribution of scientific production about breast reconstruction

\begin{tabular}{|c|c|c|c|c|c|c|}
\hline Name of country & $\begin{array}{c}\text { No. of articles } \\
(\%)\end{array}$ & $\begin{array}{c}\text { Total } \\
\text { citations }\end{array}$ & $\begin{array}{l}\text { Total citations } \\
\text { without } \\
\text { self-citation }\end{array}$ & $\begin{array}{l}\text { Average } \\
\text { citations per } \\
\text { article }\end{array}$ & $\begin{array}{l}\text { Percent of } \\
\text { self citations } \\
(\%)\end{array}$ & $\begin{array}{c}\text { Prevalence of } \\
\text { breast cancer } \\
\text { (per } 100,000 \\
\text { females) }\end{array}$ \\
\hline United States & $1,408(43.20)$ & 20,436 & 6,003 & 14.51 & 71 & 76 \\
\hline United Kingdom & $354(10.86)$ & 2,404 & 1,518 & 6.79 & 37 & 89.1 \\
\hline Germany & $158(4.85)$ & 1,149 & 920 & 7.27 & 20 & 81.8 \\
\hline Italy & $148(4.54)$ & 938 & 635 & 6.34 & 32 & 86.3 \\
\hline France & $122(3.74)$ & 936 & 645 & 7.67 & 31 & 99.7 \\
\hline Australia & $114(3.50)$ & 1,118 & 743 & 9.81 & 34 & 84.8 \\
\hline Sweden & $99(3.04)$ & 1,032 & 738 & 10.42 & 28 & 79.4 \\
\hline Japan & $91(2.79)$ & 792 & 641 & 8.7 & 19 & 42.7 \\
\hline Canada & $85(2.61)$ & 734 & 597 & 8.64 & 19 & 83.2 \\
\hline Belgium & $70(2.15)$ & 1,670 & 1,036 & 23.86 & 38 & 109.2 \\
\hline
\end{tabular}


Table 4. Top ten authors with the largest number of articles

\begin{tabular}{|lcccl|}
\hline Author & Record count & $\begin{array}{c}\text { Percentage of } \\
\mathbf{6 , 4 0 7} \text { articles (\%) }\end{array}$ & Country & Institution \\
\hline Stephen Kroll & 63 & 1.93 & US & The University of Texas \\
Warren Rozen & 56 & 1.72 & Australia & University of Melbourne \\
Mark Ashton & 43 & 1.32 & Australia & University of Melbourne \\
Maurice Nahabedian & 39 & 1.20 & US & Georgetown University \\
Robert Allen & 38 & 1.17 & US & Louisiana State University Health Sciences Center \\
Geoffrey L Robb & 38 & 1.17 & US & University of Texas \\
Joseph Disa & 34 & 1.04 & US & Memorial Sloan-Kettering Cancer Center \\
Jean Petit & 34 & 1.04 & Italy & European Institute of Oncology \\
Peter Cordeiro & 33 & 1.01 & US & Memorial Sloan-Kettering Cancer Center \\
Marie Wickman & 32 & 0.98 & Sweden & Karolinska University Hospital \\
\hline
\end{tabular}

Table 5. Top ten institutions to which breast reconstruction articles are affiliated

\begin{tabular}{|lccc|}
\hline Institution name & Country & $\begin{array}{c}\text { Record } \\
\text { count }\end{array}$ & $\begin{array}{c}\text { Percent } \\
\text { (\%) }\end{array}$ \\
\hline The University of Texas & US & 137 & 4.2 \\
Sloan Kettering Cancer Center & US & 72 & 2.2 \\
Harvard University & US & 71 & 2.2 \\
University of Melbourne & Australia & 59 & 1.8 \\
University of Michigan & US & 49 & 1.5 \\
Emory University & US & 44 & 1.4 \\
University of California, Los Angeles & US & 44 & 1.4 \\
Louisiana State University & US & 38 & 1.2 \\
Karolinska University Hospital & Sweden & 35 & 1.1 \\
Georgetown University & US & 34 & 1.0 \\
\hline
\end{tabular}

\section{DISCUSSION}

There was a trend toward an increasing number of articles on breast reconstruction despite temporary decreases at several points in time. Also, there was an accelerated growth pattern in the ratio of the number of citations to articles, proof of the increasing attraction of the medical community to the subject. As the mortality rate of women with breast cancer is decreasing $[15,16]$ and the incidence is increasing, especially in the United States $[15,17]$, there are more women with a disfigured breast due to mastectomy, and thus breast reconstruction surgery is considered a very important topic as it affects the lives of millions of women [18].

Regarding the historiography of the breast reconstruction field, 4 important clusters of articles in the evolution of this field were found. 1: There is a cluster of articles (papers are identified by the numbers in the Citation Map and Supplemental Appendix 1 [highlighted numbers: $240,309,380$, and 501]) with the topic of introducing new autologous flaps during 1990-1996 (the numbers in brackets are the number of articles in Fig. 2). In 1994, Allen and Treece [19] described the deep inferior epi- gastric perforator (DIEP) flap for use in breast reconstruction [highlighted number: 240]. The transverse rectus abdominis myocutaneous (TRAM) flap and DIEP flap are the most popular flaps for use in breast reconstruction [4]. The TRAM flap was introduced by Holmstrom [20] for the first time in 1979. Allen and Tucker [21] proposed the superior gluteal artery perforator (SGAP) free flap in 1995 [highlighted number: 380]. 2: After 1996, controversy arose about the suitable choice for flap harvest, given the donor site benefits of the DIEP flap and the vascularity benefits of the TRAM flap [4]. The articles with this topic $(576,924,933,950$, and 1,190$)$ shaped the second cluster of articles between 1996 and 2002. Nahabedian et al. [22] finally developed a classification system based on the degree of muscle sparing (MS) of the rectus abdominis muscle, which made possible the comparison of donor site complications and functional outcomes between the groups $(1,190)$ [4]. Among the methods they classified, both the MS-2 TRAM flap for breast reconstruction and the DIEP flap are widely used as primary choices for autologous breast reconstruction today [4]. 3: Within the same years, some articles with the topic of skin-sparing mastectomy (552, 561, 726, 827, 1,159, 1,161, and 1,329) also formed the third cluster. These papers introduced new methods of reduction of mastectomy scar length allowing for the transposition of incisions to sites that might have a better potential for healing and concealment [4]. 4: After 2006, flap preparation and tissue harvest for autologous breast reconstruction have also been modified with the usage of computed tomography. Articles on this topic $(1,779,1,780)$ constituted the last cluster. However, an article about the use of Doppler flowmetry in the planning of perforator flaps written in 1998 could be considered the beginning of this cluster (637).

Surgery was the most repeated subject in the publications because most of the articles introduce new techniques for this surgery and compare them [23]. Breast reconstruction offers women who have undergone mastectomy following breast can- 
cer some excellent options for creating a near-normal-appearing breast. Therefore, it has become a significant part of breast cancer management; this might be a reason why oncology is the second most popular topic in this field $[1,4,24]$.

Nine out of ten of the top journals focus on plastic surgery, consistent with the topic of the articles [25]. Plastic and Reconstructive Surgery with an impact factor of 3.1, alone included $29 \%$ of the articles. It has also published about $60 \%$ of the highly cited articles. The Annals of Plastic Surgery, the only independent journal devoted to general plastic and reconstructive surgery, with an impact factor of 1.3 , has published about $13.4 \%$ of the articles in this field. It also has the second highest rank in the number of citations per paper of highly cited articles. The Journal of Plastic Reconstructive and Aesthetic Surgery (JPRAS) is one of the world's leading international journals, covering all the reconstructive and aesthetic aspects of plastic surgery. JPRAS, with an impact factor of 1.508, ranked third with 162 articles (4.97\%) in this field. Almost all of the highly cited articles were published in professional journals of surgery or cancer and just one highly cited article was published in a general journal.

We analyzed the subject of highly cited papers (Supplemental Appendix 1). Most of the highly cited papers are surgical reports discussing various aspects of flaps. Interestingly, few papers with the subject of quality of life and emotional outcome after breast reconstruction surgery were among the highly cited papers. Other subjects which were topics of few reports in the highly cited papers were the following: 2 , radiation therapy and breast reconstruction surgery; 3 , skin-sparing mastectomy; 4, physiology of the abdominal wall after mastectomy; 5 , immediate versus late breast reconstruction; and 6, free tissue transfer. No epidemiological, molecular, or basic science studies were among these highly cited articles. No report regarding the biomaterials of implants was included in these papers.

The United States produced the largest number of articles, with about half of all of the articles we analyzed. One possible reason is that the Women's Health and Cancer Rights Act became federal law on January 1999, mandating health care payer coverage for post-mastectomy breast reconstruction and making this surgery widely available to those covered by health insurance, which might be a reason for the high volume of research on this type of surgery in the US [12]. The articles from the US also had the highest percentage of self-citation. In addition, most of the first authors were from the US. After the US, the United Kingdom, with a prevalence of 89.1; Germany, with 81.8; and Italy, with 86.3 per 100,000 females contributed to the research in this field. Belgium, with the highest prevalence of breast cancer of any country worldwide, had a very average number of citations per paper. English was the predominant language of articles on breast reconstruction, representing $95.6 \%$ of the total. Only $4.4 \%$ of the articles were not in English. The main reason is due to the widespread use of English as a language of scientific publication. It is also due to the fact that the United States and the United Kingdom were the predominant countries producing articles on breast reconstruction.

The top contributing universities or research institutions were the University of Texas, Memorial Sloan-Kettering Cancer Center, and Harvard University from the US.

This was the first breast reconstruction scientometric analysis, representing the papers' characteristics and the trends of scientific production in this field. The number of articles on breast reconstruction has increased in recent years, consistent with the number of citations. There were four clusters of articles in the development of breast reconstruction research and flaps were the subject of most of the highly cited papers.

\section{REFERENCES}

1. Djohan R, Gage E, Bernard S. Breast reconstruction options following mastectomy. Cleve Clin J Med 2008;75 Suppl 1: S17-23.

2. Blamey RW. The British Association of Surgical Oncology Guidelines for surgeons in the management of symptomatic breast disease in the UK (1998 revision). BASO Breast Specialty Group. Eur J Surg Oncol 1998;24:464-76.

3. Ahmed S, Snelling A, Bains M, et al. Breast reconstruction. BMJ 2005;330:943-8.

4. Rozen WM, Rajkomar AK, Anavekar NS, et al. Post-mastectomy breast reconstruction: a history in evolution. Clin Breast Cancer 2009;9:145-54.

5. Gainford MC, Simmons C, Nguyen H, et al. A practical guide to the management of menopausal symptoms in breast cancer patients. Support Care Cancer 2005;13:573-8.

6. Czerny V. Plastic replacement of the breast with a lipoma. Chir Kong Verhandl 1895;2:216.

7. Losken A, Jurkiewicz MJ. History of breast reconstruction. Breast Dis 2002;16:3-9.

8. Silva OE, Zurrida S. Breast cancer: a practical guide. New York: Elsevier Science; 2002.

9. Viani GA, Stefano EJ, Afonso SL, et al. Breast-conserving surgery with or without radiotherapy in women with ductal carcinoma in situ: a meta-analysis of randomized trials. Radiat Oncol 2007;2:28.

10. Jacobs LK. Lumpectomy or mastectomy: is quality of life the tie-breaker? Ann Surg Oncol 2007; 14:3035-6.

11. Chung TL, Schnaper L, Silverman RP, et al. A novel reconstructive technique following central lumpectomy. Plast 
Reconstr Surg 2006;118:23-7.

12. Wilkins EG, Alderman AK. Breast reconstruction practices in north america: current trends and future priorities. Semin Plast Surg 2004;18:149-55.

13. Hendrix D. An analysis of bibliometric indicators, National Institutes of Health funding, and faculty size at Association of American Medical Colleges medical schools, 1997-2007. J Med Libr Assoc 2008;96:324-34.

14. Hendrix D. Tenure metrics: bibliometric education and services for academic faculty. Med Ref Serv Q2010;29:183-9.

15. GLOBOCAN 2008. Breast cancer incidence and mortality worldwide in 2008 summary [Internet]. Lyon (FR); International Agency for Research on Cancer; 2011 [cited 2013 Jan 30]. Available from: http://globocan.iarc.fr/factsheets/ cancers/breast.asp.

16. Lash TL, Fox MP, Silliman RA. Reduced mortality rate associated with annual mammograms after breast cancer therapy. Breast J 2006; 12:2-6.

17. Glass AG, Lacey JV Jr, Carreon JD, et al. Breast cancer incidence, 1980-2006: combined roles of menopausal hormone therapy, screening mammography, and estrogen receptor status. J Natl Cancer Inst 2007;99:1152-61.
18. Reavey P, McCarthy CM. Update on breast reconstruction in breast cancer. Curr Opin Obstet Gynecol 2008;20:61-7.

19. Allen RJ, Treece P. Deep inferior epigastric perforator flap for breast reconstruction. Ann Plast Surg 1994;32:32-8.

20. Holmstrom $H$. The free abdominoplasty flap and its use in breast reconstruction: an experimental study and clinical case report. Scand J Plast Reconstr Surg 1979; 13:423-27.

21. Allen RJ, Tucker C Jr. Superior gluteal artery perforator free flap for breast reconstruction. Plast Reconstr Surg 1995;95: 1207-12.

22. Nahabedian MY, Momen B, Galdino G, et al. Breast Reconstruction with the free TRAM or DIEP flap: patient selection, choice of flap, and outcome. Plast Reconstr Surg 2002; 110:466-75.

23. Young VL, Watson ME. Breast implant research: where we have been, where we are, where we need to go. Clin Plast Surg 2001;28:451-83, vi.

24. Rozen WM, Ashton MW, Taylor GI. Defining the role for autologous breast reconstruction after mastectomy: social and oncologic implications. Clin Breast Cancer 2008;8:134-42.

25. Peters MA. Plastic surgery-epitomes of progress: breast reconstruction. West J Med 1982;136:524-5.

\section{Supplemental data can be found at:} http://e-aps.org/src/sm/aps-40-109-s001.pdf 


\section{Discussion}

\section{A Scientometric Analysis of 20 Years of Research on Breast Reconstruction Surgery: A Guide to Research Design and Journal Selection}

Tai Suk Roh

Department of Plastic and Reconstructive Surgery, Gangnam Severance Hospital, Yonsei University College of Medicine, Seoul, Korea

The authors have conducted a scientometric analysis of publications, breast reconstruction being the sole parameter based on a bibliographic search obtained from Institute for Scientific Information. The results showed a constant increase in the number of papers, and in the citation rate reflecting a general trend toward an increase in interest in or the frequency of actual practice of this special field of medical science.

Of note is what has been described as the time categorized four main clusters of articles: autologous flaps (1990 to 1996), donor site benefit and vascularity of deep inferior epigastric perforator flaps (1996 to 2002), skin sparing mastectomy (2002), and computed tomography imaging in flap harvest (2006-). This finding not only guides the readers on the contemporary evolution of breast reconstruction, but also poses questions regarding the future with regards to the same frame of context.

It is not surprising that the United States was the leading publication source for this subject considering the large number of cases and the leading role it has played in the development of medical expertise in this field of plastic surgery. Upon considering such data, this discussant finds it curious that a comparative analysis of publications between Occidental and Oriental literature may show some chronological or content-related differences.

I disagree with the author's assumption that the technical aspect of surgery would draw higher publication rates since the trend has been such. It would be more rational to suppose that subjects addressed with less frequency may be advantageous for future publication. Actually such areas of opportunity for publication have been listed well in the author's analysis on citation rates, where epidemiological-, molecular-, basic science-, and biomaterials-related topics showed the lowest citation rates.

In all, this article offers readers more insight and valuable information than could have been expected from glancing at the title. The authors' ingenious effort is well congratulated.

Correspondence: Tai Suk Roh

Department of Plastic and Reconstructive Surgery, Gangnam Severance Hospital, Yonsei University College of Medicine, 211 Eonju-ro, Gangnam-gu, Seoul 135-720, Korea

Tel: +82-2-2019-3421, Fax: +82-2-3463-4914, E-mail: rohts@yuhs.ac

No potential conflict of interest relevant to this article was reported.

Received: 27 Dec 2012 • Revised: 28 Dec 2012 • Accepted: 29 Dec 2012

pISSN: 2234-6163・ elSSN: 2234-6171

http://dx.doi.org/10.5999/aps.2013.40.2.116• Arch Plast Surg 2013;40:116 